\title{
O FARABEUF: ESCRIBIR EL CUERPO
}

$85-104$

Farabeuf: Writing the body

Kristov Cerda Neira*

Resumen

Se aborda la novela Farabeuf o la crónica de un instante, del escritor mexicano Salvador Elizondo, como un intento de escribir el cuerpo o desde el cuerpo. La estructura excéntrica del texto vendría a ser una expresión de este intento por subvertir las categorías culturales que determinan la narrativa en dependencia de la subjetividad (narrador, personajes, flujo de conciencia, etc.), reemplazadas por una exploración de las posibilidades semióticas de la materialidad humana.

Palabras clave: Cuerpo, subjetividad, erotismo, crueldad, escritura.

Abstract

The paper deals with the novel Farabeuf o la crónica de un instante, by the mexican writer Salvador Elizondo, as a tentative to write the body or from the body. The eccentric structure of the text would be an expression of this tentative to subvert cultural categories that determine the narrative gender as depending on Subjectivity (narrator, characters, conscience flow, etc.), now replaced with an exploration of semiotical possibilities of human materiality.

Key words: Body, subjectivity, erotism, cruelty, writing.

Farabeuf o la crónica de un instante de Salvador Elizondo (1965) es un proyecto narrativo que desafía formal y temáticamente el curso acostumbrado para su género. Como lo indica su título, intenta disponer diacrónicamente un evento singular o - como se verá - articular sincrónicamente al menos tres escenas separadas en el tiempo. Para ello formula de diversas maneras los elementos constituyentes de estas escenas, configurando la novela a través de la distribución paratáctica de estas entonaciones en nueve capítulos. Estrategia de repetición y variación que se justifica como tentativa por reconstituir en la memoria el sentido que inerva las escenas, en un recorrido circular — imitando la distribución de los hexagramas del I Ching - que se inicia y cierra con la misma pregunta: “¿Recuerdas...?”.

Las escenas son relativamente simples, no obstante, se hallan cargadas de símbolos que remiten los unos a los otros. Una de ellas corresponde al suplicio por descuartizamiento aplicado a un conspirador chino, referida a la conocida fotografía del leng-tch'é de George Dumas que Bataille popularizara en Las lágrimas de Eros (2000:248), que cierta pareja contemplase con estupefacción y fascinación a la vez. La siguiente escena incluye a otra pareja paseando por la playa; al preguntar el varón a la mujer si ella lo ama, ésta se echa a correr y recoge una estrella de mar que le inspira una sensación inquietante. Al volver a casa, la mujer encuentra en un sobre una reproducción de la fotografía aludida 


\section{Kristov Cerda}

en la escena anterior, escena que la excita sexualmente al punto que se abandona en los brazos del hombre. La última escena nos presenta al doctor Farabeuf, un famoso cirujano, acudiendo a una casa donde se encuentran dos mujeres y un hombre, presumiblemente dos de ellos son la pareja de la escena en la playa. Una de las mujeres está lanzando monedas según el uso adivinatorio del I Ching, la otra aparentemente juega con una ouija; los tres esperan a Farabeuf — quien, además, sería quien capturó la mencionada fotografía - para realizar una especie de rito donde se reproducirá teatralmente la escena sacrificial del leng-tch'é.

Para M. Glantz (1994:237), la obra de Elizondo representa una acabada expresión de cierta tendencia de la narrativa contemporánea que se caracteriza por centrarse principalmente en la reflexividad de la literatura y la perspectiva, de índole casi exclusivamente formal, que se abre al tematizar esta reflexividad en el frente del trabajo con el lenguaje y la estructura del relato. En el caso específico de Elizondo, esta perspectiva sería una consecuencia de su contacto con la Nueva Novela francesa, unida a su frecuentación de autores de la índole de Sade, Mallarmé, Joyce, Artaud y Bataille (Rosas y Madrid, 1982:8). De esta última tradición, Elizondo recoge el motivo que conecta erotismo, sacrificio y escritura, por lo que - como lo confiesa en una entrevista- Farabeuf o la crónica de un instante se constituye como un desarrollo de las posibilidades expresivas del cuerpo, entendido como un símbolo que es descifrado por el erotismo violento. Según declaraciones del autor

...cuando escribí Farabeuf la relación que intenta asimilar la imagen del supliciado con un ideograma chino se planteaba muy chocantemente. El cuerpo es uno de los artificios literarios del que se vale Georges Bataille para poder especular muchísimo, sobre todo, en la medida en que el cuerpo es continente de todas las reservas de tipo erótico, de tipo expresivo, llevado al plano en que yo pretendí llevarlas en Farabeuf, con la cirugía. Yo diría que es un prop, accesorio simbólico sumamente útil para escribir (Romero, 1989:118).

La materialidad de la escritura se pliega, así, a la materialidad del cuerpo humano, de modo que las técnicas de montaje y desmontaje que pueden afectar a uno y otro se analogan desde la perspectiva de la producción del sentido. Cirugía/sacrificio y erotismo, por lo tanto, aparecen en el texto como procesos semióticos, dada su capacidad para solicitar la materialidad del cuerpo, extrayendo sus posibilidades o incardinándola en las tramas discursivas de la cultura (sexualidad, anatomía, religión, ética, etc.).

Elizondo se arriesga a hacer hablar al cuerpo por sí mismo. Ello, sin embargo, a costa de concebirlo en términos casi exclusivamente icónicos. El paradigma de la semiotización del cuerpo se hallaría en la fotografía, en la 
medida en que ésta permite acotar la temporalidad, para estabilizar la materialidad en una superficie precisa, susceptible de interpretar al infinito por su juego significante en los códigos disponibles. Despojado de las cavidades secretas y de los movimientos psicologizantes, el cuerpo deviene, así, ícono o ideograma. Farabeuf (...) sería el ejercicio por el cual interrogamos este ideograma con una máquina de cópula y descuartizamiento

Es curioso comprobar cómo el afán de retener un recuerdo es más potente y más sensible que el nitrato de plata extendido cuidadosamente sobre una placa de vidrio y expuesto durante una fracción de segundo a la luz que penetra a través de una combinación más o menos complicada de prismas. Esa luz se concreta, como la del recuerdo, para siempre en la imagen de un momento. Una imagen borrosa, la nitidez de cuya verdadera significación, comprendida en la soledad y el silencio, es capaz de hacerte gritar en la mitad de la noche. Ese grito no es más que la máscara de tu verdadero dolor. Un dolor agudísimo, mil veces más agudo que el lento desmembramiento que ellos, con la lentitud del hielo que se resquebraja al sol, pero súbito como el vómito de un moribundo, van tajando en el cuerpo del supliciado.

La fotografía — dijo Farabeuf — es una forma estática de la inmortalidad. ${ }^{1}$

Además de la fotografia del leng-tch'é, se refieren en la novela dos imágenes que cierran el encuadre literario del cuerpo. La primera es una reproducción del cuadro llamado "Amor Sacro y Amor Profano" de Tiziano, en el que se representan dos mujeres, una completamente vestida y otra desnuda, sentadas en los extremos de un sarcófago entreabierto en el que hurga un niño. La otra imagen es la de un ideograma chino trazado en una ventana por una de las dos mujeres: 六. Este carácter, llamado Liù, nombra al número 6, auspicioso en la cultura china, y corresponde al principio pasivo/femenino o yin y alude también a las 6 líneas con las que se construyen los hexagramas sagrados del I Ching. ${ }^{2}$ Como veremos más adelante, el trazo de este ideograma se homologa en la obra a la figura del cuerpo del supliciado en el leng-tch'é y, desde allí, a la representación del cuerpo, en general.

Es posible concebir entonces a Farabeuf... como un relato donde el verdadero protagonista es el cuerpo. La escasa definición de los personajes — con excepción del Dr. Farabeuf-y la iteración obsesiva de las mismas escenas para hacerlas converger vertiginosamente unas sobre otras, reducen la trama y la espesura psicológica del relato a su mínima expresión. Es el cuerpo el que debe brillar con todo su esplendor.

${ }^{1}$ Salvador Elizondo. Farabeuf o la crónica de un instante. Madrid: Cátedra, 2000:115-116. Citaremos por esta edición.

${ }^{2}$ También son 6 las formas de escribir un carácter, 6 las formas de interpretarlo, 6 dinastías, 6 animales domésticos, 6 nombres de las direcciones en el espacio, 6 inclinaciones del deseo en el hombre, y así muchos más significados para el número seis (Lip, 1992:28ss). 


\section{EL CUERPO/SUJETO}

Para hacer del cuerpo el protagonista de la escritura es necesario destituir los privilegios que ha alcanzado el Sujeto en la novela desde el siglo XIX, alcanzados a través de procedimientos literarios que privilegian la dimensión temporal sobre la espacial (flujo de conciencia), más la confección de una interioridad para los personajes, representada en los múltiples niveles cognitivos y emotivos que suele describir un narrador omnisciente (Valles, 2008:176ss). En Farabeuf..., esto se logra al superponer el mimetismo fotográfico a la mímesis literaria. La fotografía funciona como una manera de liberar a los personajes del recurso a la conciencia, al congelar el curso temporal, de modo que en el primer plano de la narración aparece el cuerpo detenido en la singularidad del instante. Se suspende, así, la comprensión tradicional del cuerpo como un continente, para tratarlo como una superficie y un espacio, formado de detalles y remisiones concretas, que produce significados con una lógica diversa de la organización concéntrica supuesta por el Ego

Es preciso estudiar la configuración de los verdugos... es importantísimo... forman un dodecaedro con seis cúspides visibles... son seis los verdugos que actúan sobre el cuerpo del supliciado, seis... como las líneas del hexagrama... ying-yang... como el t'ai ki también: la conjunción de dos seis... Ese hombre está drogado, pero entonces ¿Por qué irradia tanta luz de su rostro?... Eres tú... fuiste tú... la simetría perfecta de la disposición de los verdugos... Ese hombre de la derecha, el Dignatario... ese hombre no es un verdugo, es evidente (225).

Que la materialidad corporal pueda producir significados al insertarla en cadenas sintagmáticas distintas de las habituales no es, con todo, una proposición subversiva. Sugerir, en cambio, que esta productividad implica reconstruir el concepto de cuerpo prescindiendo de la interioridad para transformarlo en un dispositivo desmontable, y acoplable con otros dispositivos semejantes, lanza un desafío importante a la concepción del cuerpo en nuestra cultura y, sobre todo, a la hegemonía del sujeto más allá del campo literario. Farabeuf nos pone ante la posibilidad de que el cuerpo sea el sujeto, entendiendo por esto que el cuerpo deviene el principio rector de la acción narrativa ("actante" en la terminología de Greimas) en la medida en que las formaciones semánticas vienen determinadas por la trayectoria de los cuerpos y sus encuentros en el espacio. Hemos suspendido el tiempo en el instante. La acción no es más que el efecto de montaje y yuxtaposición de los cuerpos, proyectado en la sucesión de las páginas de una novela, o en la secuencia temporal percibida por una conciencia en el plano de lo real

Cuando te detuviste estabas colocada a mi derecha. La enfermera estaba a mi izquierda. Esta colocación concordaba con la lógica del cuadro tal y como se le había reflejado en el espejo pero no como el pintor lo había concebido para ser visto por nosotros. Habías corrido hacia mi derecha, es decir, hacia el extremo 
izquierdo el cuadro — en dirección, puede decirse, a la mujer vestida—, pero en dirección a la mujer desnuda tomando como referencia la imagen reflejada del cuadro en el espejo tal y como yo la veía. Esto, sin duda, tenía un significado, sobre todo si tenemos en cuenta que la enfermera estaba colocada a mi izquierda, es decir, del lado derecho del cuadro visto de frente... (203).

Esta tendencia del texto a reemplazar una perspectiva temporal por una espacial, apoyándose también en las referencias a las imágenes arriba mencionadas, aparece ante ciertas miradas críticas como la evidencia de que la novela se modela a partir de las imágenes aludidas en ella, siguiendo el procedimiento retórico de la ekfrasis, figura que consiste en representar descriptivamente una obra plástica en el texto (Moreiras, 1999:321ss). Nosotros, sin embargo, si bien concedemos la existencia de un procedimiento de este tipo en la composición del texto, consideramos que ello - antes de subordinar la novela a los referentes plásticos- expresa el intento de constituir un relato en términos icónicos para formar una secuencia en la que quedan equiparados la fotografía del leng-tch'é, la pintura de Tiziano, los ideogramas chinos y Farabeuf, como representaciones cifradas del hecho corporal, que pueden ser interpretados en el juego de referencias que circulan de las unas a las otras. La experiencia del espacio deviene experiencia originaria cuando se ha optado a favor del Sujeto-Cuerpo contra el Sujeto-Mente, lo que también subvierte la forma de comprender la plástica, determinada ahora por la distribución en el plano de los elementos gráficos que la constituyen, de modo que el significado ya no depende de una carga semántica o simbólica reconocible por un receptor, sino más bien por los efectos producidos por la diseminación espacial de los componentes (Sarduy, 1987:316). De aquí deriva la obsesión con la ambivalencia de los caracteres chinos, que pueden ser leídos tanto iconográfica como ideográficamente

La disposición de los verdugos es la de un hexágono que se desarrolla en el espacio en torno a un eje que es el supliciado. Es también la representación equívoca de un ideograma chino, un carácter que alguien ha dibujado sobre el vaho de los vidrios de la ventana, de eso no cabe duda. Puede ser cualquiera de las dos cosas: un ideograma chino o bien un símbolo geométrico. La ambigüedad de la escritura china es maravillosa y de esa forma que se concreta allí, en la imagen del supliciado, podemos deducir el pensamiento que es capaz de convertir esta tortura en un acto inolvidable. Si aprendes a decir ese nombre comprenderás el significado del suplicio. Mira este signo:

Es el número seis y se pronuncia liú. La disposición de los trazos que lo forman recuerda la actitud del supliciado y también la forma de una estrella de mar, ¿Verdad? (226-227). 
Hexágono, cuerpo supliciado, ideograma liù, número seis, estrella de mar, a primera vista la secuencia que se traza en esta cita $-\mathrm{y}$ en el libro entero- parece una enumeración caótica, pero se constituye como paradigma por la asociación de todos estos elementos a partir de un modelo de semejanzas formales designado materialmente por el carácter 六. A cierta distancia de este conjunto circularían también los hexagramas del I Ching, "Amor Sacro y Amor Profano", ${ }^{3}$ la ouija y la estructura de seis esferas concéntricas del clatro; todos ellos aludidos en el libro, debido a similitudes con el plan de la obra (el clatro, los hexagramas, la ouija) o a consonancias con alguna de las escenas o temas descritos (el cuadro de Tiziano, en tanto contrapone dos mujeres y dos formas de erotismo). El texto ilustra, entonces, la posibilidad de construir una unidad compleja de sentido por la diseminación de elementos dispares cuya relación se sostiene, frágilmente, de una clave formal.

Al prescindir del alma como principio organizador del cuerpo, habrá que concebir su unidad desde una perspectiva semejante, esto es, como un ensamblaje que se integra en virtud de algún principio de semejanza formal o de algún flujo que inerva todas sus partes. El suplicio y la cirugía vienen a mostrarnos desde distintos frentes cómo la productividad semiótica del cuerpo descansa en el repertorio de montajes y desmontajes que admite la materia humana.

El suplicio muestra al cuerpo singularizado, en primer lugar, por el recorrido del poder, en tanto los sistemas penales que se diseñan para dirimir los conflictos, o los sistemas de saber que demandan fuentes de enunciación de acuerdo a reglas (diseñadas a su vez por el poder), señalan al cuerpo como el lugar donde los conflictos o la verdad se resuelven, en tanto el dolor posee la misma pregnancia física asociada a la evidencia. La espectacularidad de los tormentos, sea en un contexto ritual, bélico o jurídico, expone la violencia como una posibilidad material latente en cada individuo, en tanto puede ocupar indistintamente el lugar de la víctima o el del verdugo. Esta violencia no descansa sobre ideologemas morales o religiosos, sino que los antecede y los soporta en el plano de lo real, como un dato banal que se verifica en el encuentro del cuerpo con otra materia que se le resista o con otro cuerpo que se le oponga. La materialidad corporal es - por lo tantocondición de posibilidad de las formaciones políticas y discursivas, por mucho que éstas lo determinen luego con sus artefactos conceptuales. Esta precedencia lógica y real del cuerpo se funda en su ser caduco y frágil, lo que la realización del suplicio pone en evidencia con las infinitas graduaciones de dolor, corte, mutilación y desmembramiento. El cuerpo produce significados porque está, desde el primer momento, sujeto a la muerte

\footnotetext{
${ }^{3}$ Moreiras (1999:324) quisiera agregar también a la secuencia, por sus semejanzas con la fotografía del supliciado chino, "El desollamiento de Marsias", otra pintura de Tiziano.
} 
...cada vez que tu rostro se refleja en ese espejo que siempre nos ha presentido temes a la muerte, tu muerte que se esconde en esa calavera espléndida; tu muerte que es el rostro de Farabeuf, tu muerte que es la contestación a la pregunta que ella hace siempre a una tabla cubierta de letras y de números, tu muerte que ni siquiera es tu muerte porque tú no eres ni tú ni tu cuerpo, ese patrimonio aparentemente inalienable, es tu cuerpo si no un cuerpo cualquiera, el cuerpo de un desesperado que durante una ceremonia absurda no se atreve a clavar un puñal consagrado en el costado de un hombre privilegiado, de un hombre cubierto de brocados, un cuerpo cualquiera como una calle... (192).

La muerte del cuerpo es la raíz de su productividad. Se esconde en esa calavera espléndida que es el rostro intercambiable de todos. Larva cada cuerpo desde siempre, empujándolos a agenciarse los unos a los otros buscando superarla a través del sexo, con su precaria promesa de inmortalidad, o mediante el crimen, con el vértigo sangriento que infunde el poder -igualmente precario- sobre el cuerpo del otro. La referencia a las letras y los números de la ouija nos conduce en dirección de la imagen de una superficie plana, de una sola faz, llena de inscripciones que pueden interpretarse de una u otra forma, de acuerdo a las combinatorias infinitas que puedan trazar los flujos. Esta es la forma del cuerpo desde la mirada de la muerte, ella impide que el cuerpo devenga una entidad cerrada por un significado definitivo, dejándolo abierto a recibir las marcas que luego serán interrogadas como signos. La muerte, también, nos enfrenta ante la impugnación definitiva del Sujeto-Mente, pues el cuerpo puede ser embalsamado, fotografiado, reproducido por el arte, preservado más allá del instante de la muerte

Fotografiad a un moribundo - dijo Farabeuf - y ved lo que pasa. Pero tened en cuenta que un moribundo es un hombre en el acto de morir y que el acto de morir es un acto que dura un instante - dijo Farabeuf-y, que por lo tanto, para fotografiar un moribundo es preciso que el obturador del aparato fotográfico accione precisamente en el único instante en el que el hombre es un moribundo, es decir, en el instante mismo en que el hombre muere (117).

La muerte violenta aparece en Farabeuf como fulguración del cuerpo, pues expone de golpe la matriz de su productividad semiótica, alzándolo hacia un significado superior, que simula la inmortalidad al tachar al Sujeto-Mente y suspender el tiempo. La muerte violenta también convoca a los flujos del poder y el deseo a una convergencia definitiva que transfigura al cuerpo en la efigie de la víctima sacrificial, o del monstruo criminal que debe ser emasculado del organismo social. El cuerpo deviene así fetiche de sí mismo y del Sujeto-Mente ausente. La semiosis corporal se corona, entonces, con este objeto puramente estético, este ideograma, mímesis de sí mismo, del sujeto, del otro, de la vida, de la muerte, de lo sagrado, del mundo. La escena final de la novela, 


\section{Kristov Cerda}

suponiendo que éstas puedan disponerse en el tiempo, nos presenta así a una de las mujeres sometida a una intervención sadomasoquista que repite el lengtch 'é, sin que se precise jamás si se trata de una reproducción real del suplicio o sólo su teatralización

Ahora serás tú el espectáculo. Ese juego de espejos hábilmente dispuestos reflejará tu rostro surcado de aparatos y mascarillas que sirven para mantenerte inmóvil y abierta hacia la contemplación de esa imagen que tanto ansías contemplar. No desfallecerás. Tu cuerpo está bien dispuesto al contacto frío de los instrumentos. Por eso no me importa prevenirte de antemano. Imagínate a ti misma como serás entonces. Los párpados inmóviles, dilatados al máximo hacia la frente y hacia las mejillas de tal manera que tus ojos parezcan desprenderse de tu cara. Tu boca abierta en un grito hecho de tensos alambres y de potentísimos resortes descubrirá hacia el techo de este cuarto las encías lívidas y la dentadura ávida de morder la noche en una convulsión de bestia fuertemente bridada. ¿Acaso no era ésta la menos inquietante de tus premoniciones? Es una forma de entregarte como tú hubieras querido. ¿O acaso no hubieras querido regalárteme muerta? (251).

Aun cuando en el suplicio el cuerpo sea abierto para exponer la plétora de los órganos y los escondrijos entre ellos, desde la mirada de la muerte éste sigue siendo una superficie invaginada que eventualmente puede llegar a extenderse por completo sobre un plano. Por ello, junto al suplicio -o, quizás, como una forma refinada de aquel- aparece la cirugía en el texto, como una máquina de desmontaje corporal que abruma por su precisión milimétrica. En el sistema de injertos y traslapos que estructura Farabeuf aparecen sin indicaciones de contexto varias citas, ilustraciones y paráfrasis del manual quirúrgico escrito por el Farabeuf ${ }^{4}$ histórico, además de la atribución al mismo de un libro ficticio llamado Aspectos Médicos de la Tortura China (Elizondo 2000:112). ManzorCoats (1986), quien examina en detalle las estrategias intertextuales en la novela, considera que la presencia de estas referencias quirúrgicas cumple la función de perfilar a Farabeuf en torno al rasgo de la meticulosidad, así como de trazar otro paradigma que asociaría cirugía con escritura. Esta visión se enriquece al reparar en el vínculo específico que la cirugía establece con el cuerpo humano, que - pese a la asepsia generalizada - la emparenta con el ejercicio de la crueldad, pero, sobre todo, se descubre como una agresión terapéutica cuya efectividad está en directa relación con la capacidad para hacer del cuerpo un espacio plenamente visible.

${ }^{4}$ Précis de Manuel Opératoire, publicado en 1872 por Masson. Es posible encontrar hoy versiones online. 
En el acto quirúrgico cruento, el cirujano, al penetrar en el espacio anatómico del paciente, hasta entonces cerrado, al consumar su violación, abre las cubiertas que ocultan los hechos patológicos, haciendo transparente a ese cuerpo humano que, para Francisco de Quevedo, era un velo opaco (Pera, 1998:19-20. Cursivas originales).

El discurso quirúrgico se inserta en Farabeuf para revelarnos las tramas secretas del cuerpo, sus recorridos más íntimos, y proporcionarnos las claves para su desmontaje. La cirugía muestra el efecto del agenciamiento del poder y el saber anatómico sobre el cuerpo, en una máquina implacable que - a diferencia del suplicio - no requiere de justificación jurídica o teológica para vulnerar la integridad de lo humano y exponer por completo las ecuaciones nada sutiles que sostienen su estructura. Con el simple subterfugio terapéutico, la praxis quirúrgica tiene derechos casi absolutos sobre la materia humana, cedidos gustosamente por el propio paciente, que la facultan para la mayor de las obscenidades, en tanto hace visible lo que en principio desearía permanecer oculto

Mire usted, ponga atención, meta la punta de la cuchilla sobre la parte central del labio derecho de la incisión longitudinal y, a partir de allí, incida usted hacia abajo y hacia la derecha haciendo al mismo tiempo una incisión cutánea oblicua que se curve convexamente para hacerse transversal al nivel mismo de la extremidad inferior de la incisión longitudinal y que se termine en la parte posterior del brazo. Esta incisión oblicua convexa hecha en su derecha no debe interesar más que la piel, no solamente si ha cruzado los vasos axilares en el caso del brazo derecho, sino también en el caso de que no haya hecho usted más que descubrir el deltoides en el caso del brazo izquierdo (143).

Esta motivación obscena desarrolla la narración en Farabeuf, en tanto aspira a agotar las combinaciones posibles de un conjunto acotado de elementos (las tres escenas, los cuatro personajes y los elementos simbólico-plásticos) por su iteración trepidante en los nueve capítulos que la contienen. Así como los 64 hexagramas del I Ching contienen todas las mutaciones posibles del Tao, Farabeuf aspira a desenvolver la totalidad del cuerpo en un discurso finito. El suplicio, en la medida en que se subordina a una intención jurídica o sacrificial que determina el cuerpo como cifra de las esferas separadas del poder y lo sagrado, se sitúa en el devenir nocturno y femenino del yin; mientras que la cirugía, en tanto desea la iluminación total de la carne humana para salvarla, pertenece al devenir diurno y masculino del yang. Ambos devenires se acoplan formando una síntesis discursiva que inerva la crónica del instante de la transfiguración del Cuerpo-Continente en Sujeto-Cuerpo. La novela de Elizondo llegaría a postular, así, una crueldad sin sujeto (o sin más sujeto que el cuerpo) al mostrar una transgresión cruenta del cuerpo humano que no se realiza como consecuencia del deseo de un agente externo, sino que responde a la 


\section{Kristov Cerda}

lógica estructurante de conjunción-desmembramiento del propio cuerpo como máquina semiótica autónoma. Si bien es cierto que el suplicio y la cirugía aparecen como acciones deliberadas que presuponen subjetividades con intención y planeamiento, Farabeuf nos expone a la posibilidad de que los rasgos de la acción que atribuimos a la interioridad sean instituidos por un juego - relativamente azaroso- de remisiones significantes que se invisten $a$ posteriori como marcadores de identidad. Semiosis adivinatoria, en tanto produce estas identificaciones como conjeturas o postulados que se proyectan en una dimensión temporal - el Sujeto-Mente se sostiene en tanto pueda mantener su unidad en el arco que conecta pasado y futuro- por el encuentro fortuito de ciertos significantes sobre la materia

Un empeño te anima: buscas en los resquicios de la muerte lo que ha sido tu vida. Por eso las tres monedas, al caer, turban la realidad. Tres yang: nueve en el cuarto lugar del hexagrama kuai; El Hombre Desollado. La piel ha sido arrancada de sus muslos. He aquí a un hombre que sufre de una inquietud interior y que no puede permanecer en donde está. Quisiera avanzar por encima de todo, por encima de su propia muerte. Si lanzaras de nuevo cuenta las tres monedas y caerán tres yin en sexto lugar, tal vez comprenderías el significado de esa imagen, la verdad de ese instante: Cesa el llanto, llega la muerte (144).

La crueldad sin sujeto no significa entonces la inversión trivial de la polaridad mente-cuerpo, ni la impugnación arbitraria del Sujeto-Mente, sino la exposición pormenorizada de su gestación como efecto contingente de la cruenta productividad corporal. Farabeuf es también la crónica del engendramiento y la muerte del Sujeto-Mente en el instante. Crónica paradójica, en tanto aparece suspendida por la duda sobre la posibilidad de la memoria que abre y cierra el relato con la pregunta “¿Recuerdas?”. Como hemos dicho, la identidad del Sujeto-Mente depende principalmente de su persistencia en el tiempo, la que viene asegurada por la capacidad de recordar. La repetición de las escenas en el texto responde también a la necesidad de establecer el contenido de un conjunto de recuerdos que se han hecho borrosos, hasta el punto en que se dificulta asegurar si rememoran hechos reales o imaginados. Se conduce, entonces, un interrogatorio a la memoria que aparece como una potencia deformadora, de dudosa confianza, que elabora tardíamente la materia de los recuerdos (y por ende la identidad del Sujeto-Mente) incapaz de fijar al detalle la totalidad de un único evento, por lo que requiere del auxilio de la fotografía y la escritura

El olvido es más tenaz que la memoria.

Mire usted, ponga atención, es preciso que no olvide usted este delicado procedimiento. Es preciso que lo recuerde usted con todo detalle. 
Tienes que concentrarte. Esta es la regla del juego. Tienes que concentrarte para que ahora jamás lo olvides. Escucha bien esa música. Es preciso que la recuerdes. Es preciso que ese momento se fije en tu memoria. Es preciso que ahí, congelados, inmóviles, nos retengas para siempre como has retenido el rostro que viste aquella tarde ¿Recuerdas? (167).

El manto de duda que se arroja sobre los procesos identificatorios del Sujeto-Mente que están anclados en la memoria se simboliza en el texto con el espejo. Dispositivo simulador, en la medida en que infiere la existencia de una identidad interiorizada del reflejo distorsionado del cuerpo. Los recuerdos son imágenes parciales de eventos acaecidos al cuerpo, que la memoria desfigura para luego acumularlas en secuencias temporales inciertas que soportan la creencia en una subjetividad estable a lo largo de la existencia material. La mente no es más un reflejo del mundo, sino un reflejo de un reflejo, simulacro del cuerpo que se toma por su esencia secreta y fidedigna

¿Y aquel espejo enorme? Hubo un momento en que reflejó su imagen. Se tomaron de la mano y durante una fracción de segundo pareció como si estuvieran paseando a la orilla del mar, sin mirarse para no encontrar sus rostros, para no verse reflejados en esa misma superficie manchada y turbia que reflejaba también, imprecisa, mi silueta como un borrón blanquecino, inmóvil en el fondo de ese pasillo oscuro por el que Farabeuf habría de pasar apenas unos instantes después... (139).

A diferencia de la fotografía, que en el texto se legitima como la forma de preservar el evento material en su singularidad, el espejo distorsiona lo que refleja, sólo ofrece un aspecto parcial del objeto y - sobre todo - es incapaz de fijarlo. El espejo está dominado por la transitoriedad, por ello, su productividad es igual de limitada que la memoria, y sólo puede dar lugar a simulacros del cuerpo. Hay en Farabeuf una repulsa a todo lo que tenga que ver con el tiempo ordinario, que se expresa también — por ejemplo - en la tendencia a enumerar los eventos hacia atrás, en una narración regresiva que imita el rebobinado de una película cinematográfica, y de la que participan también los espejos (Gutiérrez, 2009:57ss). El Sujeto-Mente es el hijo del tiempo, atravesado de mortalidad y transitoriedad, que jamás será idéntico a sí mismo, pues no puede detenerse a voluntad en el instante y contemplar así completamente su mismidad. Es también hijo del espejo, ${ }^{5}$ en tanto toda la realidad que pueda obtener, su rostro, es derivación de la identidad que endosa al reflejo de la

\footnotetext{
${ }^{5}$ Recordemos que Lacan, en su célebre escrito sobre "El estadio del espejo" pone en relación la identificación del Sí-Mismo con la experiencia de contemplar el propio cuerpo en un espejo.
} 
Kristov Cerda

imagen corporal. Simulacro del cuerpo que sueña con el golpe mágico que lo consagre para lo real de una vez y para siempre. ${ }^{6}$

-Deberá usted hacer, entre otras muchas, las siguientes preguntas:

1) Si es que somos tan sólo la imagen en un espejo, ¿Cuál es la naturaleza exacta de los seres cuyo reflejo somos?

2) $\mathrm{Si}$ es que somos la imagen en un espejo, ¿Podemos cobrar vida matándonos?

3) ¿Es posible que podamos procrear nuevos seres autónomos, independientes de los seres cuyo reflejo somos, si es que somos la imagen en un espejo, mediante la operación quirúrgica llamada acto carnal o coito? (2000:175).

La crueldad sin sujeto desnuda al Sujeto-Cuerpo de las investiduras fantasmáticas derivadas por su simulacro. El cuerpo se hace presente por sí mismo, violentamente, hasta saturar los canales por los que se desliza el sentido. Objeto y sujeto de los flujos del deseo y del poder, materia sanguinolenta que es desmembrada una y mil veces para alimentar a los dioses imaginarios, movilizada para chocar con otros cuerpos por miríadas en las guerras, auscultada hasta el último rincón por el saber y la cirugía, que ha extirpado cada excrecencia de un alma que pudiese brotarle. El erotismo cumple en Farabeuf la función de hacer visible esta plenitud productiva del cuerpo, puesto que todos los flujos posibles de poder y deseo confluyen hacia él por sus prácticas. Sólo al erotismo le es dado condensar en los gestos concretos que circundan al acto sexual, las experiencias disímiles a las que puede entregarse toda carne, manifestándola así en su verdad más íntima. Por ello la novela de Elizondo puede ser considerada, por encima de otras denominaciones, como una novela erótica (Rosas y Madrid, 1987:22).

Tal es uno de los sentidos posibles para la representación de la pintura "Amor Sacro y Amor Profano", en tanto esta alegoría plástica yuxtapone en un mismo plano ambas formas de amor, que en el erotismo están reunidas, escindidas en la mujer enteramente desnuda y la mujer enteramente vestida que se ubican en las dos esquinas del sarcófago. Este último remite a la muerte, pero en tanto se presenta abierto y en el centro de la composición está un niño (que bien podría ser Eros) buscando o intentando tomar algo dentro; también alude a una falta y - eventualmente - a una transfiguración de lo ausente (por la referencia al "sepulcro vacío" como índice de la resurrección en los Evangelios). Hoy es sabido que el título de esta obra de Tiziano le fue dado doscientos años después, y que probablemente represente algo más pedestre, como una novia asistida por Venus y Cupido, por ejemplo (Panofsky, 2003:120ss). En el texto de Elizondo, sin embargo, se da por sentada la

${ }^{6}$ La historia de Pinocchio sería entonces, a la inversa, el relato de un cuerpo alienado que desea devenir un sujeto-mente. 
significación alegórica, no obstante también se lo percibe como una duplicación más o menos literal de las dos mujeres que aparecen en la novela. Sea cual fuere el significado de este cuadro, en Farabeuf aparece en relación con los elementos eróticos del relato, especialmente con la conexión entre el rito sacrificial y la cópula, pues el primer encuentro sexual mencionado en el libro fue incitado por la contemplación de la fotografía del leng-tch'é, y el segundo encuentro sexual - apenas insinuado - se realizaría dentro de una representación del mismo suplicio, en el que una de las mujeres aceptaría ser atada y torturada mientras se entrega al coito. El erotismo - sagrado y profano a la vez- descubre la plenitud semiótica del cuerpo, en el mismo instante en que lo muestra expuesto al desvanecimiento orgásmico o al desangramiento por el bisturí del sacrificador

Cuando cerré los ojos la fascinación de aquella carne maldita e inmensamente bella se había apoderado de mí.

(...)

Y entonces me abandoné a su abrazo y le abrí mi cuerpo para que él penetrara en mí como el puñal penetra en la herida... (142).

Erotismo y crueldad son la misma vía regia hacia la realidad del cuerpo. Expuesto como nunca antes, es reconocido ahora como el hontanar del que brotan y hacia el cual se dirigen todos los significados. "Cuerpo" es el nombre para lo que falta en el sarcófago-fuente del cuadro de Tiziano, allí hurga el infante divino para extraer la cultura y el mundo. Ideograma entre ideogramas, pero también la "cifra original" (128) de todos ellos, el tao del cuerpo demanda ser interpretado.

\section{EL CUERPO/JEROGLÍFICO}

El suplicio es una forma de escritura. Asistes a la dramatización de un ideograma; aquí se representa un signo y la muerte no es sino un conjunto de líneas que tú, en el olvido, trazaste sobre un vidrio empañado. Hubieras deseado descifrarlo, lo sé. Pero el significado de esa palabra es una emoción incomprensible e indescifrable. Nada más que una sensación a la que las palabras le son insuficientes. Tienes que embriagarte de vacío: estás ante un hecho extremo (211).

La crítica está de acuerdo en considerar a Farabeuf o la crónica de un instante como un texto especialmente metapoético (Fouques, 1981; Madrid y Rosas, 1982) que escenifica el acto de escribir a partir de sus similitudes con el erotismo y la tortura. Quisiéramos añadir que la novela nos muestra cómo estas similitudes derivan de una archiescritura (productivamente) originaria que es lo que se nombra aquí, y en el relato, como cuerpo. ${ }^{7}$ No se trata, por lo tanto, de que crueldad, sexualidad, cirugía y creación literaria — entre otros- se asocien

\footnotetext{
${ }^{7}$ Nuestra noción de archiescritura, si bien se debe a la acunación del concepto por Derrida, sigue la elaboración de la archiescritura del cuerpo realizada en el marco del psicoanálisis por Ricardo Rodulfo (1999).
} 


\section{Kristov Cerda}

exclusivamente por el solapamiento de sus estructuras, sino de que el hecho de que todos ellos repitan el acto de apremiar por la fuerza una materialidad para abrirla, marcarla, desmembrarla o recomponerla y, con ello, engendrar el sentido, responde a que este proceder es la actualización de una matriz inscripcional que se identifica con el cuerpo humano. De modo que cada una de sus operaciones emergen y retornan asiduamente a ese lugar vacante

Somos algo que ha sido olvidado. Somos una acumulación de palabras; un hecho consignado mediante una escritura ilegible; un testimonio que nadie escucha. Somos parte de un espectáculo de magia recreativa. Una cuenta errada. Somos la imagen fugaz e involuntaria que cruza la mente de los amantes cuando se encuentran, en el instante en que se gozan, en el momento en que mueren. Somos un pensamiento secreto...

$¿ \mathrm{O}$ es que somos acaso esa carta encontrada por casualidad entre las páginas de un viejo libro de medicina? (177).

La enunciación impotente del Sujeto-Mente por la anáfora del "Somos", que intenta afirmar su fantasmática existencia, articulando a la vez la enumeración de los indicios de su irrelevancia, dibuja la clave para descifrar el cuerpo como la zona de la que provienen y en la que decaen todos los sentidos. Farabeuf nos ha mostrado cómo el Sujeto es un simulacro del cuerpo, pero el que pueda ser simulado es posible sólo en tanto éste pertenece a la realidad y se halla abierto a dar o recibir sentido. Esta condición de "apertura" es la que se nos hace visible a través del sexo, el suplicio y la cirugía. Ellos señalan los puntos exactos en que las intensidades del deseo o el poder impactan en la materia para luego rebosar desde las marcas hacia la realidad. La apertura, sin embargo, no es evidente, por ello debe ser mostrada por la fuerza. El cuerpo es un jeroglífico para los otros cuerpos, que puede ser descifrado en tanto se acopla con ellos, los solicita o los violenta y viceversa. La realización de las múltiples escrituras desde su matriz inscripcional se somete a la filigrana de recorridos que van trazando estos encuentros, itinerarios que reconocemos como formaciones culturales y discursivas de toda índole. Huellas trazadas en la materia por esta orgía permanente que — como en un relato de Sade — va acumulando cuerpos sin más racionalidad aparente que la que brota de su propio deseo

"Mira...", le dije mostrándole ese cuerpo desgarrado, tratando de vencer su cuerpo con aquella visión sanguinaria, hasta que sentí que se rompía como una muñeca de barro, hasta que sentí que su cuerpo se abandonaba a mí en aquel océano de sangre que latía afuera, más allá de la ventana abierta, fuera de sus ojos cerrados que no veían otra cosa que ese cuerpo surcado de riachuelos de sangre, esa carne que tanto hubiera amado en su delirio (142).

Si la cultura y la sociedad son trazadas por el acoplamiento de los cuerpos, esto sólo es posible en tanto estos son reversiblemente desmembrables: 
"Con una cuchilla afilada se puede cortar en dos, inclusive, otra cuchilla" (163). Integrados por la composición de elementos diversos, los cuerpos pueden ser seccionados y desplegados al infinito, sólo es cosa de encontrar la cuchilla adecuada. La cirugía confluye con la escritura en el momento en que ambas funcionan desde la posibilidad de descomponer y recomponer la materia en variadas configuraciones. Ambas nos enfrentan a la apertura radical del cuerpo, que descansa en su contingencia, es decir, en que el montaje de sus partes es tan irracional como el montaje de los cuerpos. La anatomía, y otros sistemas discursivos como la biología o la economía — todos ellos prácticas escriturales, sometidas a sus propias retóricas - urden redes de racionalidad para atrapar la materia corpórea, que tarde o temprano se estrellan sobre el desafío lanzado por la muerte. La verdad del cuerpo se encuentra en el momento en que puede ser entregado al desmembramiento.

El vacío despejado por el desmembramiento posibilita el libre juego combinatorio de las partes, que no es diverso de lo que - al hablar del lenguajese ha teorizado como el juego del significante. El cuerpo se configura y reconfigura así, constantemente, como los hexagramas del I Ching, esperando a ser descifrado por acoplamientos eróticos o violentos en el transcurrir de la existencia humana. La novela explora esta condición ideográfica -0 , más bien, jeroglífica- del cuerpo que, a la vez, se resiste como demanda ser penetrado, al convocar a la narración la fotografía del suplicio, el carácter liù, la estrella de mar, etc. El cuerpo se escribe a sí mismo, la faena de esta escritura va dispersando y adhiriendo los flujos aquí o allá, para que luego la violencia del desciframiento los ponga en circulación de nuevo. La escritura literaria, la de Farabeuf, intenta representar el curso de esta archiescritura, pese a su propia advertencia respecto de la imposibilidad de enunciar la tenue escansión de los estados corporales.

Muchas veces pienso que no he pasado nada por alto, absolutamente nada, pero hay resquicios en esta trama en los que se esconde esa esencia que todo lo vuelve así: indefinido e incomprensible (155).

Si hemos de pensar en un hipotexto para Farabeuf, habría que buscar del lado de los manuales quirúrgicos publicados por el doctor francés en su época. No porque la novela lleve a cabo importantes maniobras intertextuales al respecto, sino porque es animada por la necesidad de describir exhaustivamente la actuación de la archiescritura, a fin de que sean tan explícitos sus mecanismos que luego el texto literario pueda reproducirlos. Se busca el corte longitudinal exacto, que por la magia del sincronismo, nos mostrara el instante preciso en el que es producido el sentido en la matriz inscripcional. Pero ni la repetición, ni la acumulación de símiles mecánicos o adivinatorios le permiten lograrlo, de modo que se ha de limitar a bosquejarlo, insinuarlo, como si cada uno de los capítulos constituyese una imagen parcial de la anatomía archiescritural, una especie de tomografía 
Es preciso recordarlo ahora, aquí: la identidad de ese cuerpo mutilado que de pronto había surgido ante nuestros ojos y que nosotros hubiéramos querido apresar en un abrazo inútil de muñones descarnados que anda alcanzaban a asir de otros cuerpos íntegros, pero deseosos de perderse en esa agonía lenta, hipnótica, inmóvil y erecta. Por eso hay que repetirse mil veces la misma pregunta: ¿De quién era ese cuerpo que hubiésemos amado infinitamente? (143).

Manifestación y velamiento simultáneos son los términos de la actividad comprendida por la escritura de Farabeuf en su intento por representar la archiescritura. Esta actividad corresponde a la anamorfosis, procedimiento tomado de la plástica, que consiste en esconder una imagen dentro de otra imagen, la que se hace visible solamente al modificar la perspectiva o - en algunos casos - gracias al concurso de algún aditamento óptico (Souriau, 1998:92). Fouques (1981) destaca el rol que cumple esta técnica en la obra en la medida en que los pasajes eróticos del texto siempre aluden veladamente la muerte (muerte del sentido, muerte sin más), mientras a nosotros nos parece que la totalidad de la novela emboza la representación del cuerpo como matriz inscripcional, que puede ser avistada sólo desde el cambio radical de perspectiva que estamos intentando en este estudio. La anamorfosis no constituiría, por lo tanto, sólo una técnica más del repertorio de estrategias de la escritura, sino el modo específico de representación de la semiosis corporal en la literatura, debido a la imposibilidad del lenguaje para significar la alteridad radical de la materia, no obstante obtiene su exigua fuerza performativa de aquella

El cuerpo puede inscribirse, adherirse a una banda siempre capaz de ondular, de volver sobre sí misma, el eje de simetría del rostro aparece ligeramente desplazado, dislocado; esa proporción deshecha, ese aparecer disuelto como por un hundimiento leve conducen no a la revelación de una imagen obturada, suplantada por la pantalla de la visión frontal, sino a la revelación de la anamorfosis como artificio puramente retórico que el más ligero desajuste desfocaliza, reduce a una máscara estrábica, impide significar (Sarduy, 1987:103).

Limitada por el carácter sucesivo del lenguaje, la obra se consagra entonces a los poderes de la repetición. La reiteración compulsiva de los detalles de cada escena se ordena a mostrar como en cada de una de ellas la potencia genésica del cuerpo fecunda el resto de la acción. Si bien todas las escenas compiten como escenas fundacionales de esta nueva mitología del cuerpo archi-escritor, la contemplación del leng-tch'é se muestra como la más importante, en la medida en que su estructura será imitada o aludida por las escenas posteriores. Recordemos que el momento de la pareja paseando junto al mar culmina cuando la mujer encuentra la fotografía del suplicio chino y ella enciende su deseo; y que en el momento siguiente, en el que se encuentran las dos parejas —una de ellas 100 
compuesta por el doctor Farabeuf y la "Enfermera"- se realiza el sacrificio de una de las dos mujeres a imitación de la imagen del supliciado. El leng-tch'é, cuya fotografía - desde la primera edición de 1965- aparece de manera tangible en el capítulo VII del libro, es el evento seminal de toda la obra, el instante de la fulguración del cuerpo, donde alcanza a vislumbrarse la raíz de toda inscripción

Nosotros mismos nos quedamos encerrados dentro de ese olvido hermético, infranqueable, y ella - la otra - nos mira reflejados en ese enorme espejo enmarcado en oro; nos mira a los dos que nos miramos a través del espejo y así nos comunicamos y nos tocamos con la mirada recordando ese rostro que también nos mira fijamente desde aquel día en que bajo la lluvia llegamos hasta la plazoleta en la que los verdugos se afanaban en torno al condenado, ahuyentando con voces ríspidas y entrecortadas a los perros que merodeaban en torno a la estaca ensangrentada ¿Recuerdas? Desde aquel día no sabemos cuál es el sueño, no sabemos cuál es la imagen del espejo y sólo hay una realidad: la de esas preguntas que constantemente nos hacemos y que nunca nadie ni nada ha de contestarnos (168).

Pero no todos los cuerpos son iguales. En Farabeuf hay una polarización a favor del cuerpo femenino como lugar privilegiado donde se manifiesta la archiescritura del cuerpo en general. Esta polarización replica la división entre pasividad femenina y actividad masculina, propia del tipo de pensamiento contenido en el I Ching. El principal agente de los eventos relatados es siempre el Dr. Farabeuf, quien tomó la fotografía del supliciado y quien realiza el rito eróticoquirúrgico, mientras que la mujer aparece siempre en una posición subordinada o pasiva, entregándose al amor o a la tortura. La relevancia del cuerpo femenino es tal que la obra sugiere una mutación o travestimiento de la víctima del leng-tch 'é, que previamente ha sido identificado como un varón, para demostrar que éste -al menos en el instante de su muerte - ha alcanzado la condición de una mujer

El supliciado es un hombre bellísimo. En su rostro se refleja un delirio misterioso y exquisito. Su mirada justifica una hipótesis inquietante: la de que ese torturado sea una mujer. Si la fotografía no estuviera retocada a la altura del sexo, si las heridas que aparecen en el pecho de ese individuo fueran debidas a la ablación cruenta de los senos no cabría duda de ello. Ese hombre parece estar absorto por un goce supremo, como el de la contemplación de un dios pánico (221).

El suplicio ha producido una mutación en el cuerpo del supliciado, ha pasado de ser una línea continua - yang a una línea quebrada-yin. El sacrificio patentiza así la realidad jeroglífica del cuerpo, su capacidad para producir y recibir sentidos cambiantes, que en el cuerpo femenino es más expresa debido a la posibilidad efectiva de engendrar otros cuerpos. Pero dado que la mutación no acontece en el plano real, sino exclusivamente simbólico, de 


\section{Kristov Cerda}

manera casi conjetural, comporta una maniobra travesti, quizás otra forma de anamorfosis, cuyo cambio de perspectiva nos revelaría a la mujer como potencialidad oculta en el cuerpo masculino.

El relato psicoanalítico tradicional de la constitución de la subjetividad conecta la capacidad humana de producir significados a una relación privilegiada con el falo, como índice del acceso al registro simbólico. ${ }^{8}$ Al proponer indirectamente que el cuerpo femenino es el modelo de la matriz semiótica, de modo que el varón ha de ser sometido a la castración para poder equipararlo, el texto - más que formular un discurso feminista, que es desmentido por la asimilación de la mujer a la materia y lo pasivo - nos enfrentaría al hecho de que la archiescritura acontece como el proceso de despojamiento de toda determinación morfológica - incluida la de género- hasta exhibir el cuerpo en su absoluta desnudez, es decir, en su ausencia. La mutilación sacrificial nos empujaría hacia el éxtasis en la contemplación de $W u$, el vacío

$\mathrm{Y}$ ese cuerpo inquietante, esa carne abierta hacia la vida como un fruto inmenso y misterioso que parecía haber traspuesto todos los umbrales del dolor y que nosotros contemplábamos como se contempla el curso de una estrella, o la manifestación de un portento, o la realización de un milagro (183).

En suma, el cuerpo es el origen del significado porque es un signo sagrado, un sacramento que se manifiesta en el sacrificio $-\mathrm{y}$ en el coito: "intromissio membri viri ad emissio seminis inter vaginam" (146)_. ${ }^{9}$ Estas son las formas en que se descifra, por ello Farabeuf o la crónica de un instante insiste en reproducirlas desde todos los ángulos posibles. Pero al reconocer al cuerpo descansando en el campo de lo sagrado, la mutación del supliciado continúa hasta obtener el rostro de la víctima sacrificial por antonomasia: Cristo. La palabra por quien todo fue creado, archiescritura absoluta, delirio de una semiosis transparente que consuma en su fulguración a todo el universo

Esa cara... ese rostro es soñado... no existe... ese rostro... es el amor... la muerte... es el rostro del Cristo... el Cristo chino...

(...)

Por primera vez... por primera vez... es posible sentir toda la belleza que encierra un rostro... sí, por supuesto... es una mujer... una mujer bellísima... la mujer-cristo... (224-225).

La condición de la Tierra

es la de devoción receptiva.

Así el Hombre Superior

\footnotetext{
${ }^{8}$ El falo no es el pene, sino el significante primario a partir del cual se realizaría la diferenciación de los cuerpos y también la escansión especular de la conciencia desde la que accede al lenguajeregistro simbólico (Butler, 2002:95ss).

9 "Desde la introducción del miembro viril hasta la salida del semen dentro de la vagina".
} 
lleva consigo al mundo

en la amplitud de su ser (I Ching, 1997:88).

El hexagrama Kun, Lo Receptivo, constituido por completo por líneas yin-femeninas quebradas. El cuerpo femenino es carne de sacrificio y muta hasta la determinación por el rostro absoluto, pues es la expresión material de lo receptivo. Con ello, el jeroglífico que es el cuerpo quedaría plenamente descifrado como suma del mundo. Esta es una vieja idea metafísica: el cuerpo del hombre es un microcosmos. La novela, otro microcosmos, se abriría a la revelación de que los oficios de la crueldad y el erotismo nos facultarían para vaciar - esto es, descargar en lo real- el mundo contenido en los cuerpos, en mi cuerpo, alcanzando así una identidad no dependiente de la subjetividad psicológica. Utopía del cuerpo al fin, utopía también de la escritura

Tu cuerpo es más que eso; es la extensión del mundo vista desde una altura suprema. Nadie escapa a tu huida que todo lo congela y lo vuelve inolvidable. Tu carne, cuando yo la acaricio, sabe acoger en sí misma toda la crueldad del olvido. Por eso yo no sé cómo se llama ese hombre desnudo que atado a una estaca se somete a la vida para siempre. ¿Acaso no lo adivinas en su mirada? ¿Qué importa su nombre, si, ciega, sabré toda mi vida reconocer su carne, reconocer tu cuerpo que es el suyo! (239).

Universidad Andrés Bello*

Facultad de Humanidades y Educación

Departamento de Artes y Humanidades

Fernández Concha 700, Las Condes, Santiago (Chile)

kristov.cerda@gmail.com

\section{BIBLIOGRAFÍA}

Anónimo. I Ching: El libro de los cambios. Santiago de Chile: Cuatro Vientos, 1997.

Butler, Judith. Cuerpos que importan. Buenos Aires: Paidós, 2002.

Bataille, Georges. Las lágrimas de Eros. Barcelona: Tusquets, 2000.

Derrida, Jacques. La diseminación. Madrid: Fundamentos, 1997.

Elizondo, Salvador. Farabeufo la crónica de un instante. Madrid: Cátedra, 2000.

Farabeuf, Luis Hubert. Précis de Manuel Opératoire. Paris: Masson, 1872.

Fouques, Bernard. "Farabeuf, entre l'anathème et l'anamorphose", en Bulletin Hispanique, Tome LXXXIII, № 3-4. 1981:399-431.

Glantz, Margo. Esguince de cintura: Ensayos sobre narrativa mexicana del siglo XX. México: Consejo Nacional para la Cultura y las Artes, 1994.

Gutiérrez, Luis. El tiempo en Farabeuf. México: UNAM, 2009 (Tesis de Maestría).

Lacan, Jacques. "El estadio del espejo como formador de la función del Yo", en Escritos 1. México: Siglo XXI, 1989:13-42.

Lip, Evelyn. Chinese numbers: significance, symbolism and traditions. Singapore: Times Books, 1992. 
Manzor-Coats, Lillian. "Problemas en Farabeuf mayormente intertextuales", en Bulletin Hispanique. Tomo 83, № 3-4. 1986:465-476.

Moreiras, Alberto. Tercer espacio: literatura y duelo en América Latina. Santiago de Chile: LOM, 1999.

Panofsky, Erwin. Tiziano: problemas de iconografia. Madrid: Akal, 2003.

Pera, Cristóbal. El cuerpo herido: un diccionario filosófico de la cirugía. Barcelona: Ediciones de la Universitat de Barcelona, 1998.

Rodulfo, Ricardo. Dibujos fuera del papel. De la caricia a la lectoescritura en el niño. Buenos Aires: Paidós, 1999.

Romero, Rolando. "Salvador Elizondo: escritura y ausencia del lector" (Entrevista), en La palabra y el hombre, No 71 (Julio-Septiembre 1989):117-130.

Rosas, P.; Madrid, L. Las torturas de la imaginación. México: Premiá, 1982.

Sarduy, Severo. Ensayos Generales sobre el Barroco. Buenos Aires: F.C.E.,1987.

Souriau, Etienne. Diccionario de Estética. Madrid: Akal, 1998.

Valles, José. Teoría de la narrativa. Madrid: Iberoamericana-Vervuert, 2008. 